\title{
Corrosion and Heat Transfer Characteristics of Water Dispersed with Carboxylate Additives and Multi Walled Carbon Nano Tubes
}

\author{
Chellapilla V. K. N. S. N. Moorthy ${ }^{1} \cdot$ Vadapalli Srinivas $^{2}$
}

Received: 16 September 2014/ Accepted: 12 February 2016/Published online: 27 February 2016

(C) The Institution of Engineers (India) 2016

\begin{abstract}
This paper summarizes a recent work on anticorrosive properties and enhanced heat transfer properties of carboxylated water based nanofluids. Water mixed with sebacic acid as carboxylate additive found to be resistant to corrosion and suitable for automotive environment. The carboxylated water is dispersed with very low mass concentration of carbon nano tubes at $0.025,0.05$ and $0.1 \%$. The stability of nanofluids in terms of zeta potential is found to be good with carboxylated water compared to normal water. The heat transfer performance of nanofluids is carried out on an air cooled heat exchanger similar to an automotive radiator with incoming air velocities across radiator at 5,10 and $15 \mathrm{~m} / \mathrm{s}$. The flow Reynolds number of water is in the range of 2500-6000 indicating developing flow regime. The corrosion resistance of nanofluids is found to be good indicating its suitability to automotive environment. There is a slight increase in viscosity and marginal decrease in the specific heat of nanofluids with addition of carboxylate as well as CNTs. Significant improvement is observed in the thermal conductivity of nanofluids dispersed with CNTs. During heat transfer experimentation, the inside heat transfer coefficient and overall heat transfer coefficient has also improved markedly. It is also found that the velocity of air and flow rate of coolant plays an important role in enhancement of the heat transfer coefficient and overall heat transfer coefficient.
\end{abstract}

Chellapilla V. K. N. S. N. Moorthy

krishna4u_drkist@yahoo.com; krishna.turbo@gmail.com

1 Institute of Aeronautical Engineering, Hyderabad, Telangana 500043, India

2 Gitam University, Visakhapatnam, Andhra Pradesh 530045, India
Keywords Nano particles $\cdot$ Multi walled carbon nano tubes - Thermal conductivity enhancement . Heat transfer enhancement . Overall heat transfer coefficient

\section{Introduction}

In an operation of an automotive engine only $30-35 \%$ of fuel power is converted into machine power and it is estimated that $20-30 \%$ of heat is taken away by the liquid of cooling system. With newer design of IC Engines in recent years the heat load on coolant has increased significantly and conventional coolants cannot handle that much heat loads. This increase in load on coolant results in an undesirable increase in the radiators size. Hence alternative coolant technologies need to be developed for future years.

Nanofluids are fluids dispersed with nano materials consisting of solid nano particles with sizes typically of 1-100 $\mathrm{nm}$ can be a promising future generation of heat transfer fluids. Several authors [1-21] investigated the properties of nanofluids dispersed with metal particles like $\mathrm{Cu}, \mathrm{Ag}, \mathrm{Au}, \mathrm{Pt}$, etc. and metal oxides such as $\mathrm{Al}_{2} \mathrm{O}_{3}, \mathrm{TiO}_{2}$, $\mathrm{CuO}, \mathrm{SiO}_{2}$, etc. in different base fluids, concentrations and temperatures. Based on the investigations, it can be stated that the parameters influencing nano fluid properties are particle density, particle concentration, particle size and temperature and $\mathrm{pH}$ of the fluid. All the investigators observed thermal conductivity of nanofluids increases with concentration and temperature. Das et al. [6] utilized a temperature oscillation technique for the measurement of thermal conductivity and experimentally calculated the thermal conductivity of water based nanofluids. The results indicated an increase of thermal conductivity with the 
temperature paving way for the use nanofluids in high energy density applications. Das et al. [16] obtained a comprehensive experimental data set for thermal conductivity of nanofluids with variation in nanoparticle material, base liquid, particle size, particle volume fraction and suspension temperature. The results emphasize higher enhancement in thermal conductivity with decrease in particle size and increase in temperature. It was also found that thermal conductivity enhancement is more at lower volume fractions of nanofluids.

Experimental research on the convective heat transfer performance of nanofluids has been published with various combinations of base fluids and suspensions [21-30]. The suspended nano material remarkably increased the forced convective heat transfer performance of the base fluid. At the same Reynolds number, the heat transfer of the nano fluid found to be increased with the particle volume fraction. Sahu and Chougule [26] have done studies on convective heat transfer enhancement of CNT-water nanofluid inside an automobile radiator. They found that both nano coolants exhibit enormous change in Nussult number compared to normal water. It is observed that coolant with lower $\mathrm{pH}$ exhibits better performance compared to coolant with $\mathrm{pH}$ above 7. Sahu and Chougule [27] in another paper studied the forced convective heat transfer performance of two different nanofluids $\mathrm{Al}_{2} \mathrm{O}_{3}$-water and CNT-water in an automobile radiator. The coolant flow rate is varied in the range of $2-51 / \mathrm{min}$. It is found that the heat transfer performance of CNT-water nanofluid was found to be better than $\mathrm{Al}_{2} \mathrm{O}_{3}$-water nano coolant. Teng and $\mathrm{Yu}$ [30] studied the convective heat transfer characteristics of ethylene glycol water mixture dispersed with CNTS in an air cooled radiator. The maximum enhanced ratio of heat exchange under is found to be $12.8 \%$ with a coolant flow rate of 8.5 LPM. Further, other researchers found that dispersion of MWCNTs is good compared to the SWNTs as the agglomerate size for the same base nano fluid is much smaller for MWNTs than for SWCNTs.

Most of the researchers studied the effect of normal distilled water with nano particle addition. However, normal water is not suitable as coolant in automotive systems due to its poor corrosion properties. Addition of corrosion inhibitors to water or ethylene glycol water mixtures is a normal practice to improve corrosion resistance automotive coolants. Organic additive technology is one of the methods to protect cooling system components including cylinder liners. Organic additive technology uses carboxylate corrosion inhibitors dispersed in coolants to provide protection. Carboxylate additives provide corrosion protection by chemically interacting with the metal surfaces wherever needed unlike conventional and hybrid coolants which form layers on the metals surfaces. The common carboxylate additives are sebacic acid, 2-ethylhexanoic acid, dodecanedioic acid etc., in combination with sodium nitrite as stabilizer and sodium hydroxide as $\mathrm{pH}$ buffer. Further, tolyltriazole a well-known copper corrosion inhibitor is also a common additive used in engine coolants. The influence of corrosion inhibitors on nano fluids is hitherto not cited in the literature. This paper aims to study the influence of carboxylate additives along with carbon nanotube on the physico-chemical, corrosion and heat transfer characteristics of water based automotive coolant. The flow rates of coolant are maintained in the range of 10-20 LPM higher than that mentioned in the literature.

\section{Experimental Investigations}

\section{Materials}

The MWCNTs are of $20-40 \mathrm{~nm}$ in outer diameter, $1-25 \mu \mathrm{m}$ in length and $80 \%$ purity. As received, CNTs are impure in nature containing metal particles and soot. Further because of impurities and soot they are entangled making them insoluble in water as seen from HRSEM image and EDX spectrum in Figs. 1 and 2. The soot and metal particles would spoil the surface of radiator rendering it useless. All other reagents were of analytical grade and were used without further purification.

\section{Purification and Oxidation of CNTs}

Multi-walled carbon nanotubes are highly hydrophobic in nature and do not disperse in aqueous solutions. Agglomeration would form clusters which can possibly erode the surface. Hydrophobic carbon nanotube gets deposited on the radiator surface forming black layers on the surface thereby affecting the performance of the radiator. Studies [31-39] show that oxidative techniques are best suitable to

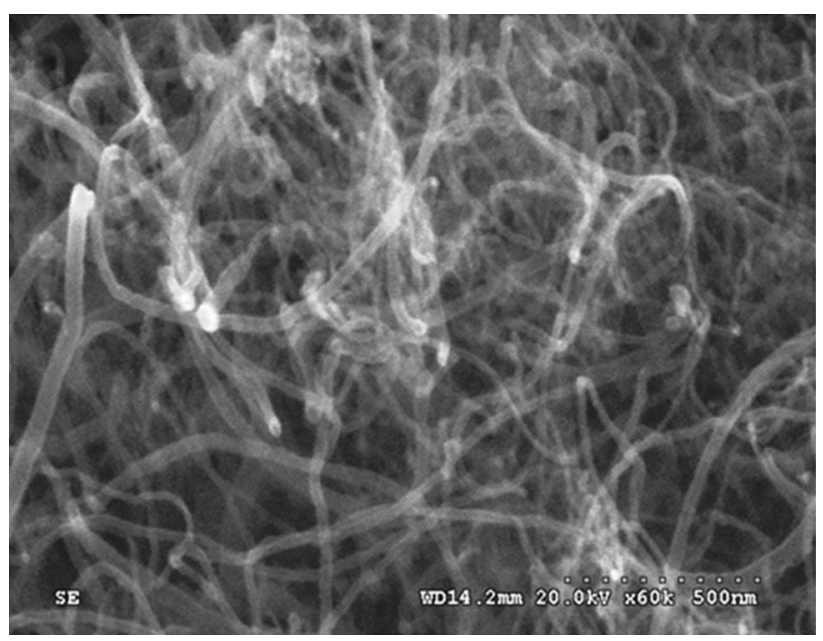

Fig. 1 HRSEM image of purified carbon nano tubes 


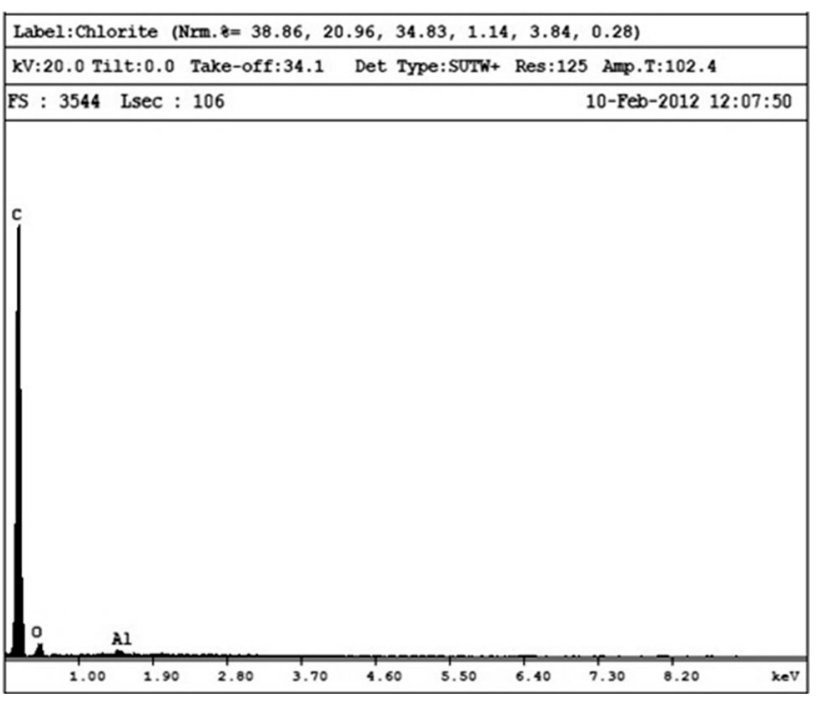

Fig. 2 EDX spectrum of pristine CNTs

purify and induce functional groups on the surface of the CNTs thereby making them hydrophilic. Pristine MWNTs were heated in air at $550{ }^{\circ} \mathrm{C}$ approximately for $2 \mathrm{~h}$ and were refluxed with concentrated hydrochloric acid for $12 \mathrm{~h}$ to remove metal particles and other impurities The mixture was then washed repeatedly with distilled water until $\mathrm{pH}$ of 7 is achieved.

The chemical oxidation process of purified MWNTs was done by refluxing CNTs in solution of 4 Molar $\mathrm{HNO}_{3}$ and $\mathrm{H}_{2} \mathrm{SO}_{4}$ (1:3 volume ratio) for $4 \mathrm{~h}$. Then, the black mixture was diluted with distilled water and washed thoroughly with DI water until neutral $\mathrm{pH}$ value is obtained. The black solid was dried in the vacuum oven at $50{ }^{\circ} \mathrm{C}$ for overnight. Oxidation of CNTs introduces carboxyl groups on the surface which make them readily dispersible in water and other polar solvents. Low concentrations of acids and less reflux time are employed to prevent damage of chemical structure.

The CNTs are characterized using HRSEM-EDX for structure \& Chemical composition. Figure 3 shows HRSEM-EDX image of purified entangle free CNTs. and Fourier Transform infrared spectroscopy for presence of functional groups. Figure 4 shows FTIR Spectrum of oxidized CNTs. The Treated CNTs show peaks at 1120 and $1750 \mathrm{~cm}-1$, which denote carbonyl and carboxyl groups formed over the surface.

\section{Preparation of Base Fluids}

Base fluids are prepared with water and carboxylates of sebacic acid/2-ethylhexanoic acid with sodium nitrate as stabilizer and sodium hydroxide as $\mathrm{pH}$ buffer. Further to organic inhibiters, $0.1 \%$ of Tolyltriazole is added to the solution for enhanced copper and other alloy corrosion

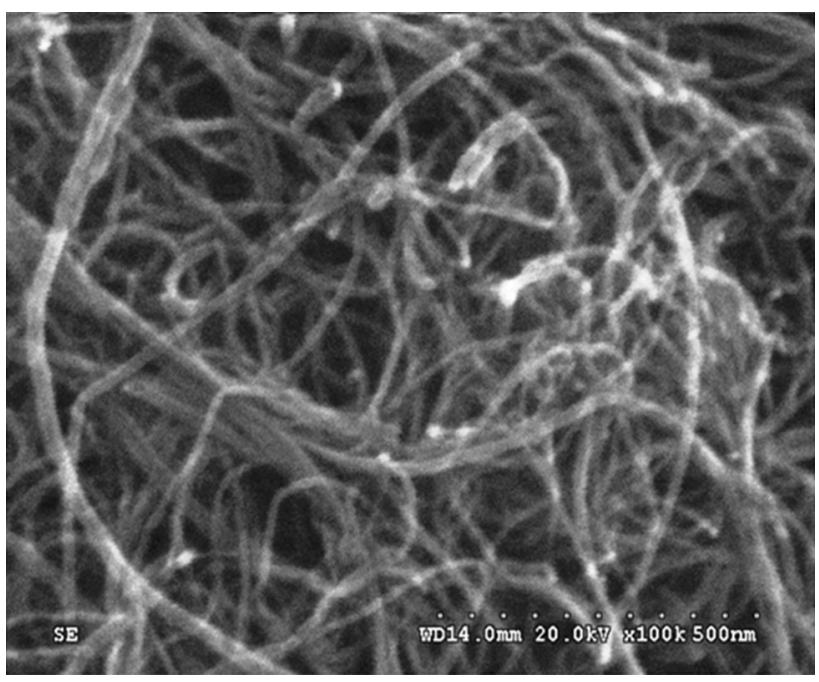

Fig. 3 HRSEM image of purified and oxidized carbon nano tubes

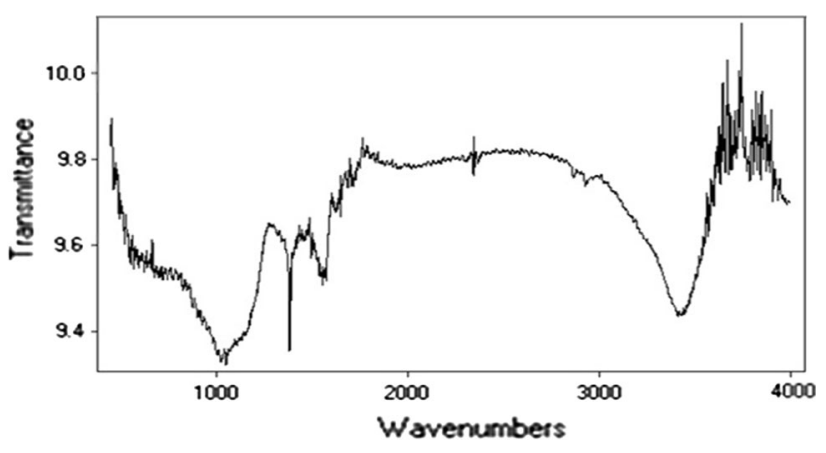

Fig. 4 FTIR spectrum of oxidized CNTs

protection. The $\mathrm{pH}$ of the solution is adjusted to 8 . sebacic acid and 2-ethylhexanoic acid are mixed in concentrations of 1 and $2 \%$ in water and named as COOLANT 1, COOLANT 2, COOLANT 3 and COOLANT 4 respectively. The fluids are tested for corrosion resistance as per ASTM D 1384 Glassware corrosion test.

\section{Glassware Corrosion Tests}

This test method employed to evaluate coolants that are definitely deleterious to automotive environment due to corrosion. The test also analyzes the corrosive behavior of CNTs in automotive coolants. In this test method, specimens of metals typical of those present in engine cooling systems viz., copper, solder, brass, cast iron, mild steel and aluminum are totally immersed in aerated engine coolant solutions mixed with corrosive water for $336 \mathrm{~h}$ (14 days) at $88{ }^{\circ} \mathrm{C}$. The corrosion inhibitive properties of the test solution are evaluated on the basis of the weight changes incurred by the specimens. Each test is run in triplicate, and the average weight change is determined for each metal. The results obtained are tabulated in Table 1 . 
Table 1 Corrosion results of base coolants

\begin{tabular}{llcrrr}
\hline Coupon & \multicolumn{2}{l}{ Weight loss $(\mathrm{mg})$} & & \\
\cline { 2 - 6 } & Standard values & COOLANT 1 & COOLANT 2 & COOLANT 3 & COOLANT 4 \\
\hline Copper & 10 & 0.33 & 1.33 & 0.83 & 1.83 \\
Solder & 30 & 52.33 & 11.33 & 422.33 & 6.83 \\
Brass & 10 & 2.83 & 2.83 & 8.66 & 5.33 \\
Mild steel & 10 & 0.66 & 6.66 & 12.33 & 9.66 \\
Cast iron & 10 & 1.33 & 0.68 & 367.21 & 267.83 \\
Aluminium & 30 & 72.16 & 21.16 & 267.66 \\
\hline
\end{tabular}

Table 2 Corrosion results of coolant dispersed with CNTs

\begin{tabular}{lcccc}
\hline Coupon & \multicolumn{3}{l}{ Weight loss (mg) } & \\
\cline { 2 - 5 } & Base fluid (COOLANT2) & Base fluid + 0.025 \% CNTs & Base fluid + 0.05 \% CNTs & Base fluid + 0.1 \% CNTs \\
\hline Copper & 1.33 & 1.33 & 1.33 & 1.33 \\
Solder & 11.33 & 10.33 & 10.667 & 10.667 \\
Brass & 2.83 & 2.667 & 2.66 & 2.667 \\
Mild steel & 6.66 & 6.33 & 6.33 & 6.33 \\
Cast iron & 0.68 & 0.55 & 0.667 & 0.667 \\
Aluminium & 21.16 & 20.667 & 20.167 & 20.333 \\
\hline
\end{tabular}

From the results, it can be found that water COOLANT 2 which is a mixture of $2 \%$ sebacic acid, sodium nitrite, sodium hydroxide and tolyltriazole gave best protection against corrosion to all the metal.

Hence COOLANT 2 is selected as base coolant for dispersion with nano materials.

\section{Nanofluid Preparation}

Nanofluids are prepared by dispersing low weight fractions of CNTs with COOLANT 2 as base fluid using an Ultra probe sonicator. Low weight fractions are chosen since higher weight fractions will increase the viscosity and thereby increasing the pumping power of the fluid. Oxidized CNTs in are added to water and sonicated for $30 \mathrm{~min}$ so that a uniform dispersion is achieved. CNTs in $0.025,0.05$ and $0.1 \%$ weight concentration are dispersed in base fluid and tested for corrosion behavior. The results are shown in Table 2 .

From the above results, it can be found that dispersion of CNTs does not affect the anti-corrosive properties of carboxylated water and hence are suitable in automotive environment.

\section{Stability of Nanofluids}

The stability of colloidal dispersions is related in terms of zeta potential of the fluid. The zeta potential indicates the degree of repulsion between adjacent, similarly charged
Table 3 Zeta potential of narmal water and carboxylated water with CNTs

\begin{tabular}{ll}
\hline Sample & Zeta potential $(\mathrm{mV})$ \\
\hline Water $+0.025 \%$ CNTs & 20.5 \\
Water $+0.1 \%$ CNTs & 18.8 \\
Carboxylated water $+0.025 \%$ CNTs & 38.2 \\
Carboxylated water $+0.1 \%$ CNTs & 30.11 \\
\hline
\end{tabular}

particles $(\mathrm{OH}, \mathrm{COOH}$ groups present in CNTs and the medium. A value of \pm 25 indicates incipient stability of colloid and any value above 25 and below -25 indicate good stability of the solution. The zeta potential of normal water and carboxylated water dispersed with oxidized CNTs is evaluated to assess the effect of carboxylates on stability.

From the results shown in Table 3, it can be found that CNTs are more stable in water with carboxylates than that with normal water.

\section{Mesurement of Thermophysical Properties}

The thermo physical properties viz., thermal conductivity, specific heat and dynamic viscosity are of paramount importance in evaluating the performance of heat exchanger. The Thermo physical properties of base fluids and nanofluids are measured and the effect of CNTs dispersion is analyzed. 


\section{Thermal Conductivity Measurement}

A KD2 Pro thermal property analyzer that uses the transient line heat source method (similar to transient hot wire method) is used to measure thermal conductivity of water and nanofluids. Since water has very less viscosity, turbulence occurs at temperatures above $50{ }^{\circ} \mathrm{C}$ and hence the measurement could be carried out in the temperature range of $30-50{ }^{\circ} \mathrm{C}$. The following equations give the variation of thermal conductivity with temperature from room temperature to $50{ }^{\circ} \mathrm{C}$.

It is found that the improvement in thermal conductivity from base fluid at $50{ }^{\circ} \mathrm{C}$ with $0.025 \%$ CNTs is $8.12 \%$, with $0.05 \%$ CNTs is $14.58 \%$ and with $0.1 \%$ is $17.85 \%$. The data for different mass fractions is correlated using 2nd order polynomial equations as given below. The validation of Eqs. 1, 2, 3 and 4 can be seen in Fig. 5.

Water:

$$
\begin{aligned}
\mathrm{k}= & 0.5652+1.801 \mathrm{E}-3[\mathrm{~T}]-5.183 \mathrm{E}-6[\mathrm{~T}]^{2} \\
& \text { Water }+0.025 \% \text { CNTs: } \\
\mathrm{k}= & 0.5685+2.654 \mathrm{E}-3[\mathrm{~T}]-1.854 \mathrm{E}-7[\mathrm{~T}]^{2} \\
& \text { Water }+0.05 \% \text { CNTs: } \\
\mathrm{k}= & 0.579+3.318 \mathrm{E}-3[\mathrm{~T}]-7.341 \mathrm{E}-6[\mathrm{~T}]^{2} \\
& \text { Water }+0.1 \% \text { CNTs: } \\
\mathrm{k}= & 0.593+3.872 \mathrm{E}-3[\mathrm{~T}]-6.351 \mathrm{E}-6[\mathrm{~T}]^{2}
\end{aligned}
$$

The data of thermal conductivity variation with temperature is found to be following the trend of 2 nd order polynomial. Hence, the data is further extrapolated so that the equations can be used for mathematical modeling of heat transfer data.

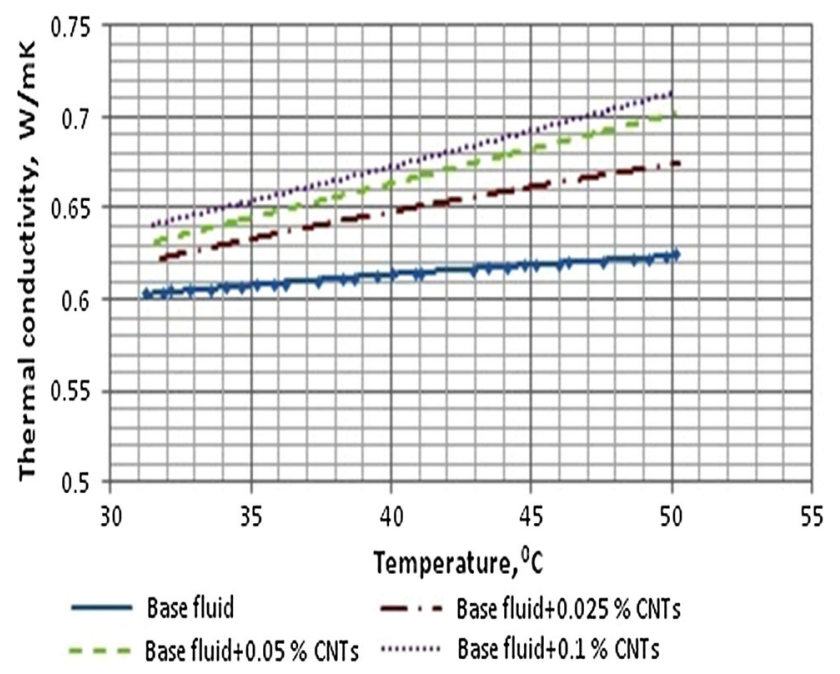

Fig. 5 Validation of Eqs. 1, 2, 3 and 4
Table 4 Specific heat results of base fluid and various combinations of nanofluids

\begin{tabular}{lll}
\hline S. no & Fluid & Specific heat $(\mathrm{Cp})$ \\
\hline 1 & Base fluid & 4.223 \\
2 & Base fluid $+0.025 \%$ CNTs & 4.185 \\
3 & Base fluid $+0.05 \%$ CNTs & 4.178 \\
4 & Base fluid $+0.1 \%$ CNTs & 4.165 \\
\hline
\end{tabular}

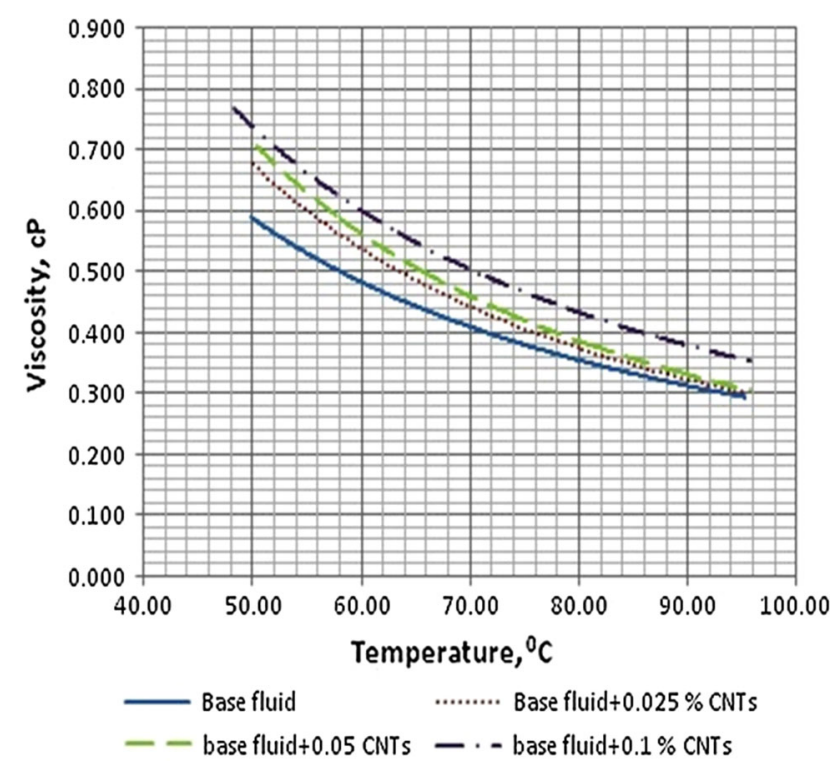

Fig. 6 Variation of viscosity with temperature

\section{Measurement of Specific Heat and Absolute Viscosity}

KD2 pro setup can also be used to measure the specific heat of carboxylated water and nano fluids. Since the CNTs are dispersed in very low concentrations, the effect of CNTs on specific heat is marginal. The specific heat results are tabulated in Table 4.

The absolute viscosity of carboxylated water and nanofluids is measured using Brookfield cone \& plate LVDV-iii+ ultra rheometer. The absolute viscosity is measured in the range of $50-95^{\circ} \mathrm{C}$. The variation of viscosity with temperature is shown in Fig. 6.

As evident from the graph, at lower temperature, the increase in viscosity is considerably and it is around 13.5, 16 and $24 \%$ respectively for $0.025,0.05$ and $0.1 \%$ mass fractions.

However, at higher temperatures, the increase in viscosity is marginal at $1,4.5$ and $7.5 \%$ respectively. The increase in viscosity is less since lesser mass fraction of CNTs are used in preparation of nanofluids. 


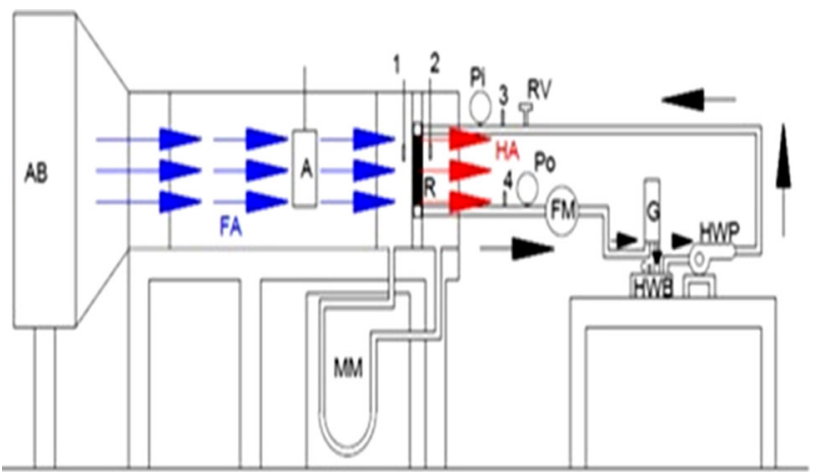

Fig. 7 Schematic diagram of test rig

\section{Experimental Set Up for Heat Transfer Enhancement}

The test rig used in the study is an air cooled heat exchanger similar to a car radiator. The Schematic diagram of the test rig is shown in Fig. 7. Heat transfer coefficients $\&$ overall heat transfer coefficient will be measured and the performance of the fluid will be rated.

The experimental test rig contains an Air Flow Duct, Air Blower (AB), Anemometer (A), Radiator (R), Flow Meter (FM), Geyser (G), Hot Water Boiler (HWB), Hot Water Pump set (HWB), Regulating Valve (RV), Manometer (MM), Pressure Gauge At Inlet Of Radiator (PI), Pressure Gauge At Outlet Of Radiator (PO). Further, thermocouple $1,2,3$ and 4 measure the temperatures of air at Inlet $\left(\mathrm{T}_{\mathrm{C} 1}\right)$, Out Let $\left(\mathrm{T}_{\mathrm{C} 2}\right)$ and temperature of coolant at inlet $\left(\mathrm{T}_{\mathrm{H} 1}\right) \&$ outlet $\left(\mathrm{T}_{\mathrm{H} 2}\right)$ of Radiator. The sensitivity of thermocouple is $0.1{ }^{\circ} \mathrm{C}$ with an error of $0.2-0.3 \%$.

Air blower is fitted at one end of the duct and the other end is fitted with the radiator. Anemometer is fitted between blower and radiator to measure the speed of air. A flow meter is fitted at the out let of the radiator to measure the flow rate of the coolant coming out of the radiator. Air is blown at velocities of 5,10 and $15 \mathrm{~m} / \mathrm{s}$ similar to the automobile motion against the air. The coolant is heated using a combination of hot fluid Geyser and Hot water boiler before the inlet of the radiator. The maximum heat that can be given to the fluid or the fluid loses is $5 \mathrm{~kW}$.

The radiator consists of 36 tubes with OD $7 \mathrm{~mm}$ and ID $5.5 \mathrm{~mm}$. The length of the tubes is $294 \mathrm{~mm}$. A total of 212 fins are on the radiator core with fin thickness $0.6 \mathrm{~mm}$, Fin Width $23 \mathrm{~mm}$ and Fin Length $329 \mathrm{~mm}$. The maximum discharge of coolant is 20 LPM. The hydraulic diameter used to calculate the flow Reynolds number of coolant is taken as $5.5 \mathrm{~mm}$ which is the inner diameter of the radiator tubes. Twelve number of thermocouples (T5-T16) are fitted in radiator core at different locations to measure temperatures on the tubes and fins as shown in Fig. 8. The average of $\mathrm{T} 5-\mathrm{T} 1$ will give the mean wall temperature $\mathrm{T}_{\mathrm{W}}$ of the core of radiator. Using the energy balance between the air and the coolant the heat transfer parameters are evaluated.

The experiments are conducted with carboxylated water as base fluid and base fluid dispersed with MWCNTs at various concentrations of MWCNTS 0.025, 0.05 and $0.1 \%$. The data is taken with a varying air velocity of 5,10 and $15 \mathrm{~m} / \mathrm{s}$ the flow rate of fluid is varied as 10,15 and 20 LPM corresponding to a flow Reynolds number of 2500-6000. The Temperature of fluid is maintained in the range of $80-95{ }^{\circ} \mathrm{C}$. At each parameter setup all the temperatures are noted using Data logger attached to the test rig. The experiment is repeated for all possible variations of the set up varying the three parameters viz., concentration of MWCNTs, velocity of air over radiator and the flow rates of coolant or nano fluid in the radiator.

\section{Evaluation of Heat Transfer Coefficient, $h_{i}$ and Overall Heat Transfer Coefficient, $\mathbf{U}_{i}$}

The heat transfer coefficient $h_{i}$ and overall heat transfer coefficient ' $U$ ' is a measure of the overall ability of a series
Fig. 8 Radiator with locations of 12 thermocouples on core
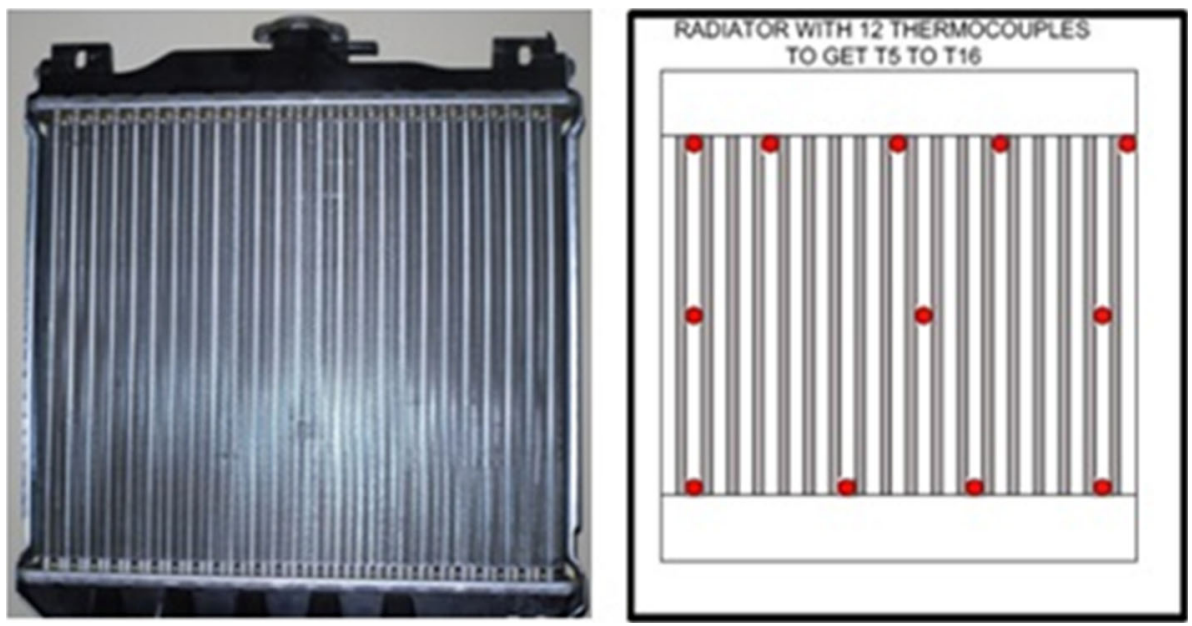
Table 5 Percentage enhancement of $U_{i}$ for various concentrations of MWCNTs at $5 \mathrm{~m} / \mathrm{s}$ air velocity

\begin{tabular}{|c|c|c|c|c|c|c|c|c|}
\hline \multirow[t]{2}{*}{$\mathrm{V}(\mathrm{m} / \mathrm{s})$} & \multirow[t]{2}{*}{$\operatorname{Re}$} & \multirow{2}{*}{$\begin{array}{l}\text { Base fluid } \\
\mathrm{Ui}\left(\mathrm{W} / \mathrm{m}^{2} \mathrm{~K}\right)\end{array}$} & \multicolumn{2}{|c|}{ Base fluid $+0.025 \%$ MWCNTs } & \multicolumn{2}{|c|}{ Base fluid $+0.05 \%$ MWCNTs } & \multicolumn{2}{|c|}{ Base fluid $+0.1 \%$ MWCNTs } \\
\hline & & & $\mathrm{Ui}\left(\mathrm{W} / \mathrm{m}^{2} \mathrm{~K}\right)$ & $\%$ Change & $\mathrm{Ui}\left(\mathrm{W} / \mathrm{m}^{2} \mathrm{~K}\right)$ & $\%$ Change & $\mathrm{Ui}\left(\mathrm{W} / \mathrm{m}^{2} \mathrm{~K}\right)$ & $\%$ Change \\
\hline \multirow[t]{9}{*}{$5 \mathrm{~m} / \mathrm{s}$} & 2500 & 453.16 & 662.08 & 46.1 & 826.05 & 82.3 & 883.07 & 94.9 \\
\hline & 3000 & 483.61 & 682.83 & 41.2 & 858.00 & 77.4 & 930.72 & 92.5 \\
\hline & 3500 & 514.06 & 703.58 & 36.9 & 889.95 & 73.1 & 978.37 & 90.3 \\
\hline & 4000 & 544.51 & 724.33 & 33.0 & 921.90 & 69.3 & 1026.02 & 88.4 \\
\hline & 4500 & 574.96 & 745.08 & 29.6 & 953.85 & 65.9 & 1073.67 & 86.7 \\
\hline & 5000 & 605.41 & 765.83 & 26.5 & 985.80 & 62.8 & 1121.32 & 85.2 \\
\hline & 5500 & 635.86 & 786.58 & 23.7 & 1017.75 & 60.1 & 1168.97 & 83.8 \\
\hline & 6000 & 666.31 & 807.33 & 21.2 & 1049.70 & 57.5 & 1216.62 & 82.6 \\
\hline & 6500 & 696.76 & 828.08 & 18.8 & 1081.65 & 55.2 & 1264.27 & 81.4 \\
\hline Average & & 574.96 & 745.08 & 30.8 & 953.85 & 67.1 & 1073.67 & 87.3 \\
\hline
\end{tabular}

Table 6 Percentage enhancement of $U_{i}$ for various concentrations of MWCNTs at $10 \mathrm{~m} / \mathrm{s}$ air velocity

\begin{tabular}{|c|c|c|c|c|c|c|c|c|}
\hline \multirow[t]{2}{*}{$\mathrm{V}(\mathrm{m} / \mathrm{s})$} & \multirow[t]{2}{*}{$\operatorname{Re}$} & \multirow{2}{*}{$\begin{array}{l}\text { Base fluid } \\
\text { Ui (W/m² K) }\end{array}$} & \multicolumn{2}{|c|}{ Base fluid $+0.025 \%$ MWCNTs } & \multicolumn{2}{|c|}{ Base fluid $+0.05 \%$ MWCNTs } & \multicolumn{2}{|c|}{ Base fluid $+0.1 \%$ MWCNTs } \\
\hline & & & $\mathrm{Ui}\left(\mathrm{W} / \mathrm{m}^{2} \mathrm{~K}\right)$ & $\%$ Change & $\mathrm{Ui}\left(\mathrm{W} / \mathrm{m}^{2} \mathrm{~K}\right)$ & $\%$ Change & $\mathrm{Ui}\left(\mathrm{W} / \mathrm{m}^{2} \mathrm{~K}\right)$ & $\%$ Change \\
\hline \multirow[t]{9}{*}{$10 \mathrm{~m} / \mathrm{s}$} & 2500 & 493.30 & 697.55 & 41.4 & 785.90 & 59.3 & 834.37 & 69.1 \\
\hline & 3000 & 548.25 & 743.75 & 35.7 & 849.10 & 54.9 & 901.47 & 64.4 \\
\hline & 3500 & 603.20 & 789.95 & 31.0 & 912.30 & 51.2 & 968.57 & 60.6 \\
\hline & 4000 & 658.15 & 836.15 & 27.0 & 975.50 & 48.2 & 1035.67 & 57.4 \\
\hline & 4500 & 713.10 & 882.35 & 23.7 & 1038.70 & 45.7 & 1102.77 & 54.6 \\
\hline & 5000 & 768.05 & 928.55 & 20.9 & 1101.90 & 43.5 & 1169.87 & 52.3 \\
\hline & 5500 & 823.00 & 974.75 & 18.4 & 1165.10 & 41.6 & 1236.97 & 50.3 \\
\hline & 6000 & 877.95 & 1020.95 & 16.3 & 1228.30 & 39.9 & 1304.07 & 48.5 \\
\hline & 6500 & 932.90 & 1067.15 & 14.4 & 1291.50 & 38.4 & 1371.17 & 47.0 \\
\hline Average & & 713.10 & 882.35 & 25.4 & 1038.70 & 47.0 & 1102.77 & 56.0 \\
\hline
\end{tabular}

of conductive and convective barriers to transfer heat. It is closely related to heat transfer performance of heat exchangers. It is evaluated using the following equations

$q=\dot{m} C_{P n f}\left[T_{h 1}-T_{h 2}\right]=h_{i} A_{i}\left(T_{B}-T_{w}\right)=U_{i} A_{i} \Delta T_{l m}$

where

$\Delta T_{l m}=\frac{\left[\left(T_{H 1}-T_{C 1}\right)-\left(T_{H 2}-T_{C 2}\right)\right]}{\ln \left[\left(T_{H 1}-T_{C 1}\right) /\left(T_{H 2}-T_{C 2}\right)\right]}$

Reynolds number, $\operatorname{Re}=\frac{4 \dot{m}}{\pi D \mu_{l}}$

\section{Results and Discussion}

The specific heat and viscosity of carboxylated water and nano fluids are taken from the measured values as given in the previous section. The variation of, inside heat transfer coefficient $\left(\mathrm{h}_{\mathrm{i}}\right)$ and inside overall heat transfer coefficient $\left(U_{i}\right)$ with Reynolds number of carboxylated water and air velocity is analysed for carboxylated water and different combinations of carboxylated water and MWCNTs.

Dispersion of CNTs in carboxylated water has a profound effect on both inside heat transfer coefficient and overall heat transfer coefficient. The enhancement with addition of CNTs is significant at every value of Reynolds Number. The results from the data collected at $5 \mathrm{~m} / \mathrm{s}$ are tabulated for various Reynolds Numbers in Table 5. The results from the data collected at $10 \mathrm{~m} / \mathrm{s}$ are tabulated for various Reynolds Numbers in Table 6. Compared to an air velocity of $5 \mathrm{~m} / \mathrm{s}$ the improvement in $U_{i}$ and $h_{i}$ is slightly lower at $10 \mathrm{~m} / \mathrm{s}$ velocity. The results from the data collected ay $15 \mathrm{~m} / \mathrm{s}$ are tabulated for various Reynolds Numbers in Table 7. The enhancement in $U_{i}$ and $h_{i}$ with addition of CNTs with $15 \mathrm{~m} / \mathrm{s}$ air velocity is lower than that with 5 and $10 \mathrm{~m} / \mathrm{s}$ velocity.

The results clearly indicate the influence of air velocity and flow Reynolds number of the coolant. As the air velocity and flow Reynolds number increases, there is a slight reduction in the improvement. Further, with increase 
Table 7 Percentage enhancement of $U_{i}$ for various concentrations of MWCNTs at $15 \mathrm{~m} / \mathrm{s}$ air velocity

\begin{tabular}{|c|c|c|c|c|c|c|c|c|}
\hline \multirow[t]{2}{*}{$\mathrm{V}(\mathrm{m} / \mathrm{s})$} & \multirow[t]{2}{*}{$\operatorname{Re}$} & \multirow{2}{*}{$\begin{array}{l}\text { Base fluid } \\
\text { Ui }\left(\mathrm{W} / \mathrm{m}^{2} \mathrm{~K}\right)\end{array}$} & \multicolumn{2}{|c|}{ Base fluid $+0.025 \%$ MWCNTs } & \multicolumn{2}{|c|}{ Base fluid $+0.05 \%$ MWCNTs } & \multicolumn{2}{|c|}{ Base fluid $+0.1 \%$ MWCNTs } \\
\hline & & & $\mathrm{Ui}\left(\mathrm{W} / \mathrm{m}^{2} \mathrm{~K}\right)$ & $\%$ Change & $\mathrm{Ui}\left(\mathrm{W} / \mathrm{m}^{2} \mathrm{~K}\right)$ & $\%$ Change & $\mathrm{Ui}\left(\mathrm{W} / \mathrm{m}^{2} \mathrm{~K}\right)$ & $\%$ Change \\
\hline \multirow[t]{9}{*}{$15 \mathrm{~m} / \mathrm{s}$} & 2500 & 567.11 & 782.48 & 38.0 & 909.00 & 60.3 & 967.16 & 70.5 \\
\hline & 3000 & 646.46 & 846.98 & 31.0 & 965.80 & 49.4 & 1028.71 & 59.1 \\
\hline & 3500 & 725.81 & 911.48 & 25.6 & 1022.60 & 40.9 & 1090.26 & 50.2 \\
\hline & 4000 & 805.16 & 975.98 & 21.2 & 1079.40 & 34.1 & 1151.81 & 43.1 \\
\hline & 4500 & 884.51 & 1040.48 & 17.6 & 1136.20 & 28.5 & 1213.36 & 37.2 \\
\hline & 5000 & 963.86 & 1104.98 & 14.6 & 1193.00 & 23.8 & 1274.91 & 32.3 \\
\hline & 5500 & 1043.21 & 1169.48 & 12.1 & 1249.80 & 19.8 & 1336.46 & 28.1 \\
\hline & 6000 & 1122.56 & 1233.98 & 9.9 & 1306.60 & 16.4 & 1398.01 & 24.5 \\
\hline & 6500 & 1201.91 & 1298.48 & 8.0 & 1363.40 & 13.4 & 1459.56 & 21.4 \\
\hline Average & & 884.51 & 1040.48 & 19.8 & 1136.20 & 31.8 & 1213.36 & 40.7 \\
\hline
\end{tabular}

in flow Reynolds number of the fluid from 2500 to 6500 the improvement in the heat transfer coefficient and overall heat transfer coefficient from base fluid has gradually reduced. The effect of mass fraction of CNTs is also markedly visible as evident from Tables 5,6 and 7 . The improvement overall heat transfer coefficient $\left(U_{i}\right)$ and inside heat transfer coefficient $\left(\mathrm{h}_{\mathrm{i}}\right)$ is more as the mass fraction increases.

\section{Conclusions}

From the study the following conclusions are drawn as follows.

1. Water dispersed with $2 \%$ sebacic acid could give good corrosion protection.

2. CNTs dispersed in carboxylated water did not alter the corrosion behavior and hence are suitable to automotive environment.

3. The zeta potential of carboxylated water dispersed with CNTs is found to be better compared to normal water dispersed with CNTs.

4. Dispersion of CNTs could improve the thermal conductivity and thereby the heat transfer characteristics of nanofluids

5. Carboxylated water dispersed with $0.025,0.05$ and $0.1 \%$ of CNTs could improve the heat transfer characteristics of nanofluids.

6. Improvement in heat transfer is dependent upon the air velocity and flow Reynolds number of the liquid.

7. The improvement overall heat transfer coefficient $\left(\mathrm{U}_{\mathrm{i}}\right)$ and inside heat transfer coefficient $\left(\mathrm{h}_{\mathrm{i}}\right)$ is affected by mass fraction of CNTs.

8. The improvement in heat transfer coefficient and overall heat transfer coefficient with nanofluids is more in near laminar region.
Acknowledgments The authors gratefully acknowledge the financial assistance received from Hindustan Petroleum Corporation Ltd., for conducting the tests on the heat exchanger at GITAM University.

\section{References}

1. M.J. Assael, C.F. Chen, I. Metaxa, W.A. Wakeham, Thermal conductivity of suspensions of carbon nanotubes in water. In International Journal of Thermophysics. Proceedings of the 15th Symposium on Thermophysical Properties, Part II 25(4), p. 971-985 (2004)

2. X.H. Chen, C.S. Chen, Q. Chen, F.Q. Cheng, G. Zhang, Z.Z. Chen, Non-destructive purification of multi-walled carbon nanotube produced by catalyzed CVD. Mater. Lett. 57(3), 734-738 (2002)

3. S.U.S. Choi, Enhancing thermal conductivity of fluids with nanoparticles. Dev. Appl. Non-Newton. Flows ASME 231, 99-105 (1995)

4. S.U.S. Choi, Z.G. Zhang, W. Yu, F.E. Lockwood, E.A. Grulke, Anomalous thermal conductivity enhancement in nanotube suspensions. Appl. Phys. Lett. 79, 2252-2254 (2001)

5. M. Chopkar, S. Sudarshan, P.K. Das, I. Manna, Effect of particle size on thermal conductivity of nanofluid. Miner. Met. Mater. Soc. ASM Int. 39(7), 1535-1542 (2008)

6. S.K. Das, N. Putra, P. Thiesen, W. Roetzel, Temperature dependence of thermal conductivity enhancement for nanofluids. ASME Trans. J. Heat Transf. 125(4), 567-574 (2003)

7. S.K. Das, S.U.S. Choi, H.E. Patel, Heat transfer in nanofluids-a review. Heat Transf. Eng. 27(10), 3-19 (2006)

8. V. Datsyuk, M. Kalyva, K. Papagelis, J. Parthenio, D. Tasis, A. Siokou, I. Kallitsis, C. Galiotisa, Chemical oxidation of multiwalled carbon nanotubes. Carbon 46(6), 833-840 (2008)

9. Y. Ding, H. Alias, D. Wen, R.A. Williams, Heat transfer of aqueous of carbon nanotubes (CNT nanofluids). Int. J. Heat Mass Transf. 49(1-2), 240-250 (2006)

10. J. Eapen, W.C. Williams, J. Buongiorno, L.W. Hu, S. Yip, Meanfield versus microconvection effects in nanofluid thermal conduction. Phys. Rev. Lett. 99, 095901(1-4) (2007)

11. J.A. Eastman, S.U.S. Choi, S. Li, W. Yu, L.J. Thompson, Anomalously increased effective thermal conductivities of ethylene glycol-based nanofluids containing copper nanoparticles. Appl. Phys. Lett. 78(6), 718-720 (2001)

12. S.Z. Heris, M.N. Esfahany, G. Etemad, Investigation of $\mathrm{CuO} /$ water nano fluid laminar convective heat transfer through a circular tube. J. Enhanc. Heat Transf. 13(6), 279-289 (2006) 
13. S.Z. Heris, M.N. Esfahany, S.G.H. Etemad, Experimental investigation of convective heat transfer of $\mathrm{Al}_{2} \mathrm{O}_{3} /$ water nano fluid in circular tube. Int. J. Heat Fluid Flow 28(2), 203-210 (2007)

14. K.S. Hong, T.K. Hong, H.S. Yang, Thermal conductivity of Fe nanofluids depending on the cluster size of nanoparticles. Appl. Phys. Lett. 88(3), 031901 (2006)

15. P.X. Hou, S. Bai, Q.H. Yang, C. Liu, H.M. Cheng, Multi-step purification of carbon nanotubes. Carbon 40(1), 81-85 (2002)

16. H.E. Patel, T. Sundararajan, S.K. Das, An experimental investigation into the thermal conductivity enhancement in oxide and metallic nanofluids. J. Nanopart. Res. 12(3), 1015-1031 (2010)

17. I.D. Rosca, F. Watari, M. Uo, T. Akasaka, Oxidation of multiwalled carbon nanotubes by nitric acid. Carbon 43(15), 3124-3131 (2005)

18. P. Keblinski, J.A. Eastman, D.G. Cahill, Nanofluids for thermal transport. Mater. Today 8(6), 36-44 (2005)

19. D.H. Kumar, H.E. Patel, V.R.R. Kumar, T. Pradeep, S.K. Das, Model for heat conduction in nanofluids. Phys. Rev. Lett. 93(14), 144301 (2004)

20. W.Y. Lai, P.E. Phelan, S. Vinod, P. Ravi, Convective heat transfer for water-based alumina nanofluids in a single $1.02-\mathrm{Mm}$ tube. In 11th Intersociety Conference on Thermal and Thermomechanical Phenomena in Electronic Systems, IEEE 2008, p. $970-978$

21. S. Lee, S.U.S. Choi, S. Li, J.A. Eastman, Measuring thermal conductivity of fluids containing oxide nanoparticles. J. Heat Transf. 121(2), 280-289 (1999)

22. L. Vaisman, W.H. Daniel, G. Marom, The role of surfactants in dispersion of carbon nanotubes. Adv. Colloid Interface Sci. 128-130, 37-46 (2006)

23. F.D.S. Marquis, L.P.F. Chibante, Improving the heat transfer of nanofluids and nanolubricants with carbon nanotubes. JOM 57(12), 32-43 (2005)

24. B.C. Pak, Y.I. Cho, Hydrodynamic and heat transfer study of dispersed fluids with submicron metallic oxide particles. Exp. Heat Transf. 11(2), 151-170 (1998)

25. R. Prasher, W. Evans, P. Meakin, J. Fish, P. Phelan, P. Keblinski, Effect of aggregation on thermal conduction in colloidal nanofluids. Appl. Phys. Lett. 89, 143119 (2006)

26. S.S. Chougule, S.K. Sahu, Thermal performance of automobile radiator using carbon nanotube-water nanofluid-experimental study. J. Therm. Sci. Eng. Appl. 6(4), 041009 (2014)
27. S.S. Chougule, S.K. Sahu, Comparative study of cooling performance of automobile radiator using $\mathrm{Al}_{2} \mathrm{O}_{3}$-water and carbon nanotube-water nanofluid. J. Nanotechnol. Eng. Med. 5(1), 011001-1-011001-5 (2014)

28. S. Sarkar, R.P. Selvam, Molecular dynamics simulation of effective thermal conductivity and study of enhanced thermal transport mechanism in nanofluids. J. Appl. Phys. 102, 074302 (2007)

29. S. Ozerinc, S. Kakac, A.G. Yazicioglu, Enhanced thermal conductivity of nanofluids : a state-of-the-art review. Microfluid. Nanofluid. 8(2), 145-170 (2010)

30. T.-P. Teng, C.-C. Yu, Heat dissipation performance of MWCNTs nano-coolant for vehicle. Exp. Therm. Fluid Sci. 49, 22-30 (2013)

31. M.V. Naseh, A.A. Khodadadi, Y. Mortazavi, O.A. Sahraei, F. Pourfayaz, S.M. Sedghi, Functionalization of carbon nanotubes using nitric acid oxidation and DBD plasma. World Acad. Sci. Eng. Technol. 3, 151-153 (2009)

32. D. Wen, Y. Ding, Experimental investigation into convective heat transfer of nanofluids at the entrance region under laminar flow conditions. Int. J. Heat Mass Transf. 47(24), 5181-5188 (2004)

33. W. Williams, J. Buongiorno, L.W. Hu, Experimental investigation of turbulent convective heat transfer and pressure loss of alumina/water and zirconia/water nanoparticle colloids (nanofluids) in horizontal tubes. J. Heat Transf. 130(4), 042412 (2008)

34. X.-Q. Wang, A.S. Mujumdar, Heat transfer characteristics of nanofluids: a review. Int. J. Therm. Sci. 46(1), 1-19 (2007)

35. Y. Xuan, Q. Li, Investigation on convective heat transfer and flow features of nanofluids. J. Heat Transf. 125(1), 151-155 (2003)

36. Y. Yang, Z.G. Zhang, E.A. Grulke, W.B. Anderson, G. Wu, Heat transfer properties of nano particle-in-fluid dispersions (nanofluids) in laminar flow. Int. J. Heat Mass Transf. 48(6), 1107-1116 (2005)

37. Y.-C. Chiang, W.-H. Lin, Y.-C. Chang, The influence of treatment duration on multi-walled carbon nanotubes functionalized by $\mathrm{H}_{2} \mathrm{SO}_{4} / \mathrm{HNO}_{3}$ oxidation. Appl. Surf. Sci. 257(6), 2401-2410 (2011)

38. F.P. Incropera, D.P. Dewitt, Fundamentals of Heat and Mass Transfer (Wiley, New York, 1996)

39. W.M. Kays, M.E. Crawford, Convective Heat and Mass Transfer (McGraw-Hill Inc., New York, 1993) 